Revista NEP - Núcleo de Estudos Paranaenses, Curitiba, v.5, n.1, jun. 2019

\title{
MEMÓRIA, HISTÓRIA E EMANCIPAÇÃO POLÍTICA DE PONTAL DO PARANÁ (PR)
}

\author{
Ana Elisa Penha ${ }^{1}$ \\ Marisete Teresinha Hoffmann-Horochovski ${ }^{2}$ \\ Edson Armando Silva ${ }^{3}$ \\ Mayã Polo Campos ${ }^{4}$
}

\begin{abstract}
Resumo: Este artigo analisou o processo de emancipação política de Pontal do Paraná, litoral paranaense. A partir do conceito municipalização e da descrição do território, procurou responder ao questionamento: Qual o contexto em que ocorre o processo de emancipação de Pontal do Paraná? Para respondê-lo, foi utilizado como instrumento de coleta de dados a história oral, por meio de entrevistas com atores-chave do processo emancipatório e que podem resgatá-lo através da memória. Os dados foram trabalhados por meio da metodologia de análise das redes de significados das entrevistas e de suas categorias. Com isso, foram levantados aspectos relativos à história e cultura do território e de suas comunidades. Os resultados apontaram que essa emancipação ocorreu diante de um contexto institucional favorável, em especial devido à influência exercida pelo legislativo estadual e pelas características constitucionais da época.
\end{abstract}

Palavras-chave: Pontal do Paraná. Memória. Analise de redes. Emancipação municipal.

\section{MEMORY, HISTORY AND POLITICAL EMANCIPATION OF PONTAL DO PARANÁ (PR)}

\begin{abstract}
This article analyzed the process of political emancipation of Pontal do Paraná, paranaense coast. From the concept of municipalization and the description of the territory, it sought to answer the question: What is the context in which the process of emancipation of Pontal do Paraná takes place? To answer this question, oral history was used as a tool for collecting data, through interviews with key actors of the emancipatory process and who can rescue it through memory. The data were worked through the methodology of analysis of the networks of meanings of the interviews and their categories. With this, aspects related to the history and culture of the territory and its communities were raised. The results pointed out that this emancipation took place against a favorable institutional context, especially due to the influence exerted by the state legislature and the constitutional characteristics of the time.
\end{abstract}

Keywords: Pontal do Paraná. Memory. Network analysis. Municipal emancipation.

\footnotetext{
${ }^{1}$ Mestre em Desenvolvimento Territorial Sustentável pela Universidade Federal do Paraná - Setor litoral.

2 Doutora em Sociologia pela Universidade Federal do Paraná. Professora no Mestrado em Desenvolvimento Territorial Sustentável (PPGDTS/UFPR) e no Mestrado Profissional de Sociologia (ProfSocio/UFPR).

${ }^{3}$ Doutor em História pela Universidade Federal Fluminense. Professor adjunto da Universidade Estadual de Ponta Grossa. Editor da Revista de História Regional.

${ }^{4}$ Pesquisadora no Programa de Doutorado em Geografia da Universidade Estadual de Ponta Grossa. Membro do grupo de Estudos Territoriais.
} 


\section{Introdução}

A municipalização é um acontecimento que engendra dinâmicas de disputa e alteração do espaço a partir de um contexto histórico e institucional. Em Pontal do Paraná, litoral paranaense, este foi o primeiro grande movimento político institucionalizado no território, sendo referenciado como nascimento político e histórico do munícipio.

O recente desmembramento de Paranaguá, em 1995, viabilizou o estudo do fenômeno através do questionamento: Qual o contexto em que ocorre o processo de emancipação de Pontal do Paraná? Partiu-se do pressuposto que a resposta seria capaz de tanto promover a caracterização e reconhecimento identitário do lugar, quanto de resgatar o contexto institucional (os aspectos constitucionais e os arranjos políticos) do processo. A pesquisa possibilitaria, portanto, refletir sobre as bases do nascimento do município em questão, além de contribuir para o aprofundamento dos estudos de processos emancipatórios com a utilização de uma metodologia diferenciada, a análise de redes semântica. Os resultados alcançados a partir desta questão norteadora são apresentados ao longo do texto.

É importante lembrar que Pontal do Paraná é um dos sete municípios do litoral do Paraná e está posicionado geograficamente ao lado de Paranaguá, cidade que abriga o maior porto graneleiro da América Latina e terceiro maior porto de contêineres do Brasil. Diante do modo de ocupação da região e por possuir um calado marítimo natural de 24 metros, a especulação portuária passou a fazer parte da história de Pontal, contrastando com o potencial ambiental, cultural e turístico que apresenta. Sua extensa costa marítima, a maior do estado, é mantida através da Unidade de Conservação Parque Natural municipal da Restinga. Já o Parque Natural de Manguezais preserva as condições e paisagens genuínas do lugar. Há diferentes comunidades tradicionais (pesqueiras), a exemplo de Barrancos e Ilha do Maciel, e comunidades indígenas no município. De forma geral, as potencialidades da região e as consequências das ações para com ela justificam os diferentes estudos sobre o município.

$\mathrm{O}$ artigo está dividido em quatro partes, além dessa breve introdução. $\mathrm{Na}$ primeira é detalhada a metodologia que embasou a pesquisa, com destaque para a utilização das redes semânticas. Na segunda, é discutida teoricamente a municipalização no Brasil, especialmente pós Constituição Federal de 1988. Na terceira é analisado o processo de emancipação de Pontal do Paraná e, por fim, são apresentadas as considerações finais. 


\section{Metodologia}

A história oral, por meio da história de vida e da história temática, foi tomada como metodologia capaz de resgatar os universos pessoais e, por extensão, os coletivos. A história de vida propicia que aspectos mais subjetivos sejam levantados na medida em que o entrevistado narra livremente sobre sua vida, relacionando-a com o contexto sóciohistórico e, por conseguinte, permitindo análises sócio-histórico-culturais menos possíveis por outras fontes. A história temática se refere a um tema específico, préestabelecido pelo pesquisador, sobre um determinado tema ou acontecimento vivenciado ou conhecido pelo pesquisado (SANTOS; ARAÚJO, 2007).

A história oral permite captar “o indizível” (QUEIROZ, 1987), bem como a reflexão do próprio sujeito sobre sua realidade e o assunto a ser abordado, além da manifestação de dados subjetivos como: "ideias, crenças, maneiras de pensar, opiniões, sentimentos, maneiras de sentir, maneiras de atuar, condutas; projeções para o futuro, razões conscientes ou inconscientes de determinadas atitudes ou comportamentos" (MINAYO, 2007, p. 65).

Por meio da oralidade, foi possível acessar a memória individual dos envolvidos no processo de emancipação de Pontal do Paraná e, conforme Halbwachs (1990), os acontecimentos e percepções que fazem parte da memória da coletividade. Ao discutir o olhar de Halbwachs, Ricouer (2007, p.13), afirma que "para lembrar, precisa-se dos outros". A memória é o reflexo da experiência de pertencimento a um grupo, posto que o indivíduo nunca está só. Sua memória está entrelaçada à memória coletiva, aos grupos e instituições com quem teve contato no decorrer de sua história.

Nesta perspectiva, foram realizadas sete entrevistas em profundidade, nas modalidades história de vida e história temática, com atores estratégicos no processo de emancipação de Pontal do Paraná, e que exerceram ou exercem o papel de representantes políticos. Seis homens e uma mulher - que residem em Pontal do Paraná (5), Paranaguá (1) e Guaratuba (1) -, foram contatados e entrevistados no período de abril a junho de 2016.

A riqueza e a quantidade de material obtido com as gravações influenciaram na escolha pela análise de redes semântica, posto que a mesma permite estabelecer tendências e diminui "a necessidade de intervenção manual do pesquisador, aumentando sua produtividade" (SILVA; SILVA, 2016, p.132). Essas ferramentas informacionais possibilitam não somente a demonstração da frequência dos termos empregados, como 
também a relação entre eles: "a ênfase no emprego de palavras e expressões revela valores e sentimentos comuns expressos em um conjunto de discursos" (SILVA; SILVA, 2016, p. 135). Possibilitam, portanto, a lapidação de uma grande quantidade de material e fornecem critérios para a análise.

Após a coleta iniciou-se o tratamento de dados, com o apoio do Grupo de Estudos Territoriais da Universidade Estadual de Ponta Grossa (Gete/UEPG). O primeiro passo consistiu em colocar todas as entrevistas transcritas num mesmo documento do pacote OpenOffice, excluindo as falas do pesquisador. Na sequência, os pontos foram substituídos por parágrafos, de forma que cada frase do entrevistado ficou em um parágrafo diferente. Com o objetivo de criar uma relação binária com cada palavra de uma frase, foi inserido um cabeçalho de identificação da frase (Id) e um cabeçalho denominado Frase, conforme apresentado no Quadro 1, que é transformado em planilha.

QUADRO 1 - ENTREVISTAS JUNTAS E PREPARADAS

\begin{tabular}{|l|l|}
\hline Id & Frase \\
\hline 1 & ah ta bem. \\
\hline 2 & eu cheguei aqui por volta de 1970. \\
\hline 3 & entao quando eu vim pra ca nao tinha nem estrada nao tinha nada tinha que vir pela praia. \\
\hline 4 & tinha uma estrada velha que vinha aqui pelo guaraguacu ne nao tinha essa nossa estrada aqui. \\
\hline 5 & a gente sofreu muito pra vim pra ca. \\
\hline
\end{tabular}

FONTE: Elaboração própria.

O passo seguinte foi criar um projeto no programa OpenRefine a partir da planilha construída. Todos os sinais de pontuação e acentuação foram retirados e as letras foram uniformizadas em minúsculas. As frases foram divididas em palavras e alocadas em diferentes linhas da tabela, bem como foram completadas as lacunas criadas, de modo a produzir uma relação entre cada palavra e a frase a que pertence através do Id. Com isso, observa-se a frequência de muitas palavras que, se descontextualizadas, não possuem sentido próprio. Essas palavras (stop words) são excluídas. Concomitantemente, são agrupadas palavras que participam de um mesmo grupo, que possuem um mesmo sentido. Assim, são unidas as palavras que compõem um mesmo significado semântico, bem como as que possuem um mesmo radical, promovendo uma diminuição no número de palavras sem alterar seu significado, conforme pode ser verificado na Figura 1. 


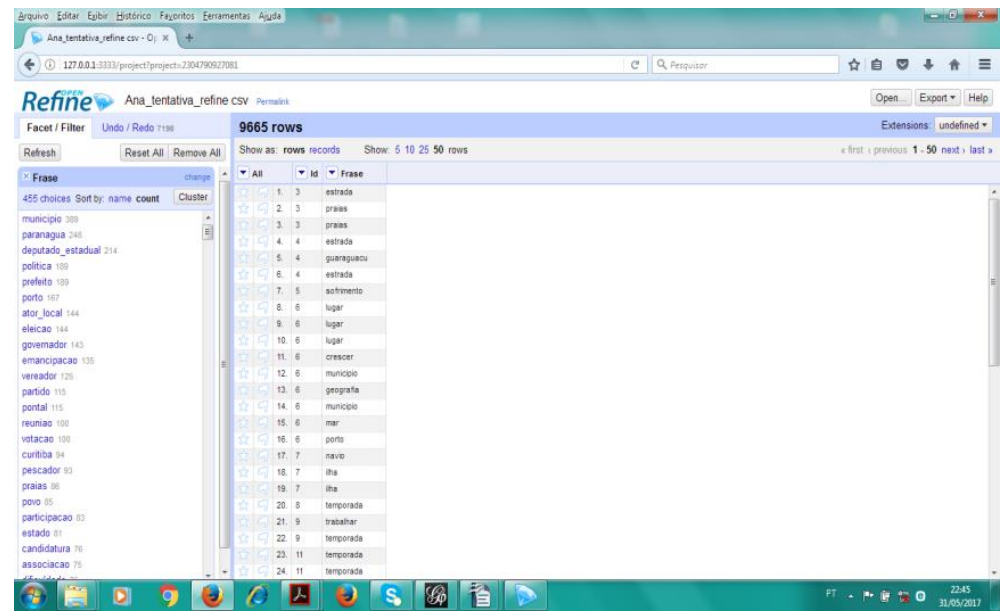

FONTE: Elaboração própria.

$\mathrm{O}$ documento, que mantem somente as palavras significativas na estrutura do discurso, foi salvo numa planilha csv para ser utilizado no software Gephi. Esse é um programa de análise de redes que, por meio de cálculos matemáticos, apresenta a leitura da realidade a partir de suas relações, sendo possível, a partir de tal construção, a análise da centralidade, da densidade, da estrutura das comunidades apresentadas. Com isso, revela-se a tendência de sentido de um conjunto discursivo, conforme apontou Silva e Silva (2016).

Por meio dos processos de importação de planilhas de nós (palavras) e arestas (ligações entre palavras), obteve-se como resposta o grafo que representa o resultado final das relações existentes no material em questão, ou seja, a frequência em que aparecem determinados termos e suas mais importantes ligações. A partir da análise dos diferentes focos proposto pelo programa e refletindo sobre o conteúdo das entrevistas, procurou-se escolher a melhor representação do grafo geral e das subcomunidades por ele representadas.

O programa Visual Understanding Environment (VUE) foi utilizado sequencialmente para criar um mapa de conceitos a partir das subcomunidades identificadas. A criação se faz a partir de uma análise intuitiva, uma vez que as categorias surgem de uma análise profunda entre a relação de cada subcomunidade semântica destacada no grafo geral do Gephi e do objetivo proposto. A questão norteadora deste estudo - Em que contexto ocorre o processo de emancipação de Pontal do Paraná? -, gerou três categorias: Memória e História, Contexto Constitucional e Processo de Emancipação. 
A partir da identificação das categorias, o texto original das entrevistas transcritas e unidas foi retomado para que fosse realizada a interpretação do discurso em unidades de sentido. Para tanto, utilizou-se o programa Rstudio através do $R Q D A-a R$ Package for Qualitativa Data Analysis. Ou seja, por meio de um retorno ao conteúdo inicial, foi realizada uma nova análise a fim de que cada um dos trechos das entrevistas fosse categorizado em uma ou mais das categorias levantas, conforme pode ser visualizado através da Figura 2:

FIGURA 2 - RQDA - CATEGORIZAÇÃO

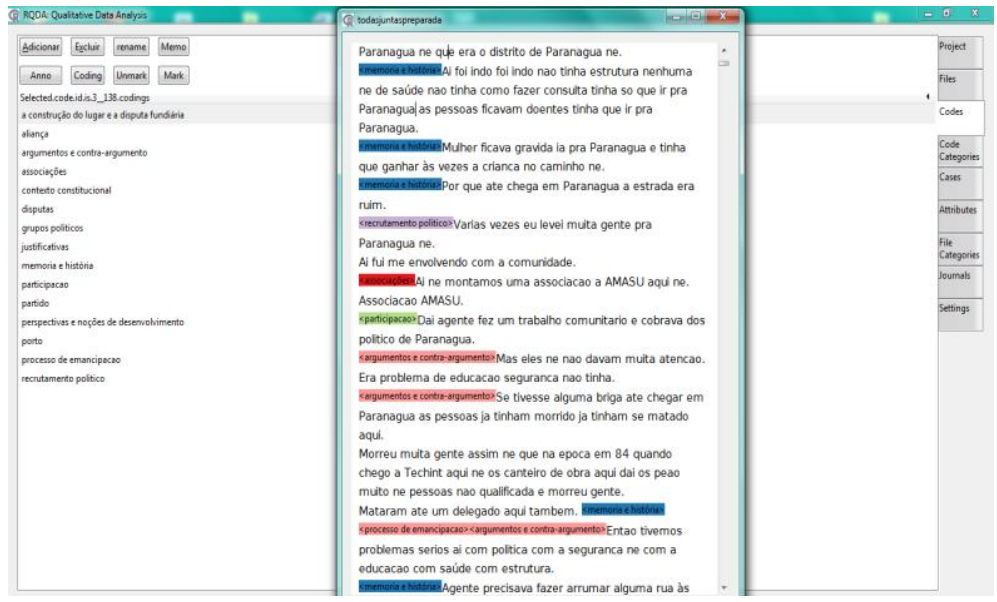

FONTE: Elaboração própria.

Novamente no Gephi, foi produzido um grafo de cada uma das categorias. Então foi possível realizar a análise de dados com base nas informações obtidas a partir do material tratado. Conforme apontado por Campos (2016), a organização visual do grafo produzido pelo Gephi está sustentada em cálculos estatísticos que possibilitam apontar as ligações e centralidades de categorias levantadas nos discursos apresentados.

Por fim, é importante ressaltar que além da análise das redes semânticas, optouse por manter algumas falas dos entrevistados, que vão ao encontro da história oral e da memória coletiva, que dizem muito sobre a memória, a história e o processo de emancipação de Pontal do Paraná.

\section{Municipalização}

Favero (2004) descreve que os municípios no Brasil foram implantados com a mesma estrutura do reino português. A organização municipal no período desempenhou um papel de apoio à colonização. Segundo Santos e Andrade (2015) a vigilância 
portuguesa se utilizava do municipalismo para conter divergências políticas e agia de modo a construir um Estado único e centralizador. Mas a presença de movimentos de rebeldia buscava o Federalismo, a descentralização e autonomia das províncias, o que impulsionou a Constituição de 1891.

Conforme Souza (2005) o federalismo esteve presente nas sete constituições brasileiras. A Constituição de 1988 reforçou o federalismo e a descentralização e reduziu a ação federal nos estados e municípios. Ampliou assim o poder local, através de legislações próprias, da participação social e do direcionamento de recursos, implementando as políticas públicas.

De acordo com Magalhães (2009), a emancipação municipal no Brasil teve início na década 1930, se intensificou nas décadas de 1950 e 1960, foi restringida no período militar (1970 e 1980) e retomada na redemocratização. No período de 1984 a 2000 foram instalados no Brasil 1.405 municípios, sendo os maiores índices localizados nas regiões Sul e Nordeste. Magalhães (2009) observa que a maioria destes, 94,5\% precisamente, possuem menos de 20 mil habitantes.

Cigolini (1999) chama atenção para o inciso $4^{\circ}$, do Artigo 18 da Constituição Federal de 1988, que determinava que:

\begin{abstract}
A Criação, a Incorporação, a Fusão e o Desmembramento de município preservarão a continuidade e a unidade do Histórico-Cultural do Meio Ambiente Urbano, far-se-ão por Lei Estadual obedecidos os requisitos previstos por Lei complementar estadual e dependerão de consulta prévia, mediante plebiscito, às populações diretamente interessadas. (BRASIL, 1988).
\end{abstract}

O autor complementa que a Constituição do estado do Paraná, promulgada em 1989, cita no Artigo 19 as condições de criação dos municípios. Em 1991, a Lei Complementar $n^{\circ}$ 56/91 explicita os requisitos para as emancipações no Paraná, entre os quais o de que a população seja superior a 5 mil habitantes. Todavia, 50\% dos novos municípios não cumpriram os requisitos mínimos exigidos. Para Cigolini (1999), mantidas as atuais exigências, as possibilidades de fragmentação chegaram a seu limite, tendência verificada com a promulgação da Emenda Constitucional n 15, de 1996, que estabelece novos critérios às emancipações. Brandt (2010) salienta que essa emenda alterou a redação do $4^{\circ}$ parágrafo do $18^{\circ}$ Artigo da Constituição Federal ao requerer que o período para criação, incorporação, fusão e desmembramento de municípios seja determinado por lei complementar federal e por consulta prévia aos municípios envolvidos e às populações interessadas. 
Citadini (1998) chama a atenção para a inviabilidade de sustentação econômica de novos municípios, o que leva a uma grande dependência do repasse estadual e federal. A dificuldade na adequada arrecadação de impostos a eles devidos é outro aspecto levantado pelo autor, que defende que para receberem os fundos federais, os municípios tenham uma arrecadação razoável. Destaca a importância do requisito criado pela Emenda $n^{\circ} 15$, sobre a necessidade de elaboração e publicação de Estudo de Viabilidade Municipal, antes do plebiscito. Diante das dificuldades encontradas por muitos municípios, levanta a possibilidade de fusão, já que por vezes são considerados os fatores políticos em detrimento da viabilidade ou não da nova criação.

Citadini (1998) relata ainda que não se deve ser contrário, em tese, à criação de novos municípios, já que países melhores administrados possuem grande número de municípios. Além disso, a população encontra nas emancipações uma nova maneira de aumentar os recursos financeiros para a comunidade, na busca de melhorias nas áreas de saúde, educação e afins. Sugere como saída um adequado modo de cobrança de impostos municipais essenciais, como o Imposto Predial e Territorial Urbano (IPTU).

Bremaeker (2013) destaca que política e administrativamente o município brasileiro é um dos mais autônomos do mundo. Porém, salienta que: 1) quanto menor o município, maior sua dependência em relação aos recursos provenientes do governo federal e dos estados; 2) quanto maior um município, maior a probabilidade de desmembramento para a criação de um novo. Em estudo sobre os motivos das emancipações realizado com prefeitos em 1992, o autor concluiu que 54,2\% se davam pelo descaso por parte da administração do município de origem, 23,6\% pela forte atividade econômica local, 20,8\% devido à grande extensão territorial do município de origem e 1,4\% em razão do aumento da população local.

Cigolini (2009) em sua pesquisa sobre 22 municípios emancipados na década de 1990 obteve como resultado que $60 \%$ dessas criações ocorreram devido às condições favoráveis, $22 \%$ em razão dos anseios da comunidade local e 18\% baseadas em plebiscito.

Magalhães (2009) destaca a aproximação dos moradores de seus representantes políticos como um importante fator presente no processo, pois, anteriormente às emancipações, em geral as mediações eram feitas com estruturas políticas distantes, dificultando a representatividade da população local.

Gomes e MacDowell (2000) demonstraram que os municípios mantêm maiores gastos com o legislativo do que a União e os estados proporcionalmente, sendo que o número menor de habitantes colabora para esse resultado. Defendem que os municípios 
muito pequenos (até 10 mil habitantes) e os micromunicípios (até 5 mil habitantes) são os grandes beneficiários da descentralização, já que recebem maior recurso por habitante do que os demais. Descrevem que a maior parte da população, $80,4 \%$, estaria sendo prejudicada diante de tal situação. Destacam que uma grande parte dos recursos dos novos municípios está direcionada a despesas administrativas em detrimento do custeio ao investimento no setor público e aplicação em programas sociais.

Magalhães (2009), por outro lado, coloca que o direcionamento de recursos às pequenas e pouco exploradas regiões possibilita o desenvolvimento das potencialidades locais e, assim, evita o êxodo às cidades maiores. Com isso, apesar de perderem recursos, as cidades maiores deixariam de ter gastos decorrentes do processo emigratório. $\mathrm{O}$ autor também observa a necessidade de estudo sobre os locais que pretendem emancipar-se, a fim de demonstrarem qual a viabilidade econômica e se ela será sustentável. Ao mesmo tempo, destaca que é necessária maior atenção por parte dos distritos administrativos, que com melhor atendimento poderiam diminuir as emancipações. A solução final para municípios em que tal processo seria inviável se daria através da fusão com outros municípios, a fim de aprimorar a estrutura político-administrativa (MAGALHÃES, 2009).

Reis, Costa e Silveira (2013) também apontam que a Constituição de 1988 serviu de alavanca para o aumento do número de municípios durante os anos 1988 a 1997. E que esse aumento, no caso de municípios de pequeno porte, pode gerar incapacidade de sustentação financeira. Isto, diante do baixo índice de geração de renda e na alta demanda de recursos dos demais âmbitos. Por outro lado, consideram que a descentralização pode aumentar uma eficaz alocação dos recursos públicos, já que possibilita a territorialização das demandas, contribuiu para a participação e o direcionamento de políticas públicas.

Para Tomio (2002), o fato de a Constituição prever autonomia aos estados na regulamentação e decisão política resulta em um dos aspectos determinantes na criação dos novos municípios. E é justamente a interferência do executivo estadual um dos principais aspectos que procura discutir. Sem a ação das lideranças locais não haveria emancipações, porém, a apreciação do processo se restringe à decisão política estadual. Nesse sentido, indica que no caso dos deputados estaduais participantes dos processos, não haveriam interesses significativos envolvidos, a não ser a continuidade da carreira política. No caso das lideranças locais, o motivo se daria em razão da ampliação do atendimento de seus interesses (reeleição, aumento da oferta de recursos físcais, 
incremento ou melhora das políticas públicas), fato que se repetiria no caso dos eleitores que passassem a interagir no processo.

Tomio (2002, p.11) sublinha o fato de que a carga tributária própria dos municípios seria incapaz de sustentar seu funcionamento e aponta: “criar um novo município continua sendo um grande negócio para as localidades do interior”. Esse arranjo oferece um papel central ao legislativo estadual em razão do veto atribuído aos deputados estaduais.

Por fim, Alves (2006) reafirma essas preposições ao concluir que a causa principal que definiu o ritmo na criação de municípios no período de 1988 a 1996 foi o amplo controle do poder legislativo estadual na condução do processo, bem como a ampliação de transferência dos recursos fiscais da União aos municípios. No caso específico de Pontal do Paraná o papel do legislativo estadual foi fundamental para o processo emancipatório, conforme abordado no próximo tópico.

\section{O processo de emancipação de Pontal do Paraná}

Rocha (1997) relata que a primeira reunião visando à emancipação do município de Pontal do Paraná ocorreu em 1985. A partir dela, em 1987 foi apresentado por um deputado estadual um projeto de lei que tinha por objetivo atender: "à vigorosa reivindicação das populações permanentes e temporárias daqueles balneários" (ROCHA, 1997, p. 30).

De acordo com o Instituto Brasileiro de Geografia e Estatística, Pontal do Paraná surgiu do desmembramento do município de Paranaguá, foi elevado à categoria de município pela lei estadual 11252 de 20 de dezembro de 1995 e instalado em 01 de janeiro de 1997 (IBGE, 2016). De acordo com o Instituto Paranaense de Desenvolvimento Social - IPARDES, o município de Pontal do Paraná possui uma área territorial de $202,159 \mathrm{~km}^{2}$, uma população estimada de 25.393 habitantes e 19.226 eleitores. Possui ainda densidade demográfica de 125,61 habitantes por $\mathrm{km}^{2}$, com taxa de crescimento populacional de 3,86\%. O Índice de Desenvolvimento Humano (IDH) é de 0,738 e Produto Interno Bruto (PIB) per capita de $\mathrm{R} \$ 17.483,00$ (IPARDES, 2017).

Após esses apontamentos, retoma-se a pergunta norteadora da pesquisa e apresenta-se os resultados condizentes com o cenário e o enredo institucional que possibilitou a mobilização. Em razão de tais pontos, as categorias história e memória, o 
contexto constitucional e o processo de emancipação inserem-se como meios de acesso à resposta que se pretendeu alcançar.

Inicia-se a discussão com a apresentação da Figura 3.

\section{FIGURA 3 - CATEGORIA MEMÓRIA E HISTÓRIA}

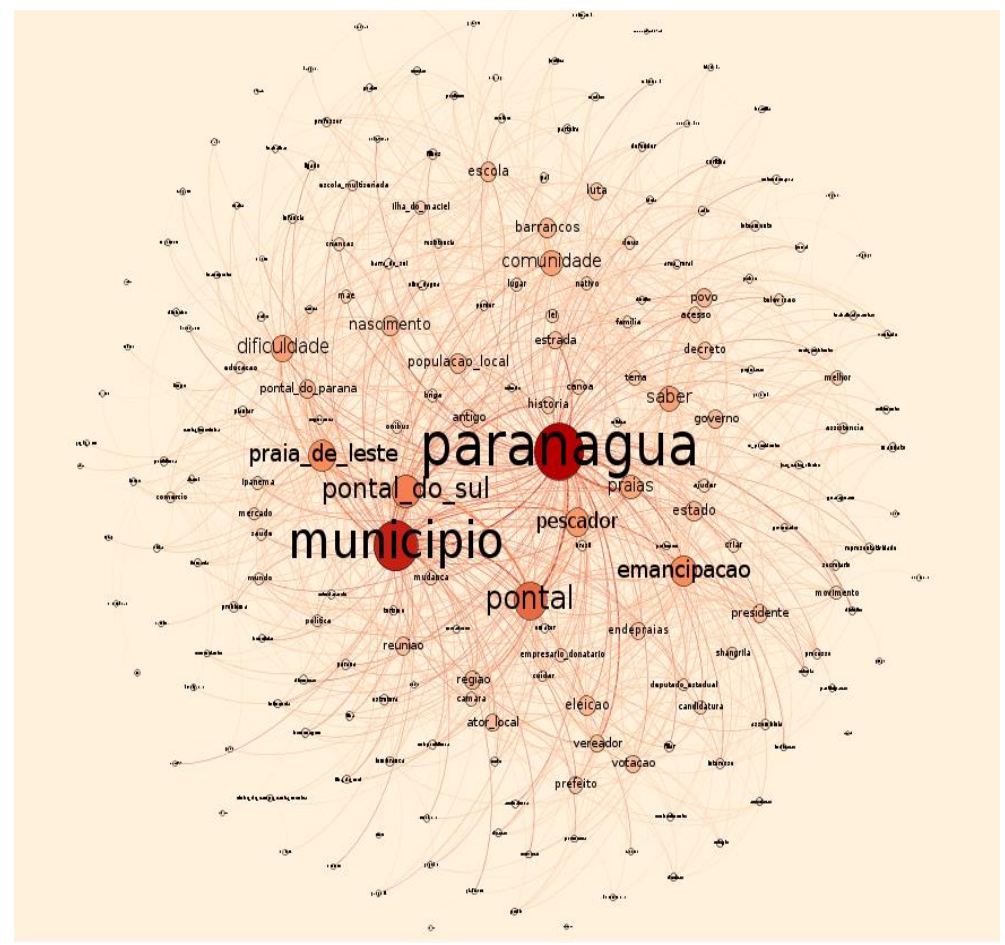

FONTE: Elaboração própria.

Conforme Campos (2016), os grafos possuem uma organização que demostra as estatísticas referentes aos discursos coletados. O tamanho das esferas está relacionado com a centralidade discursiva das falas. Dentre as estatísticas possíveis de serem analisadas, o grau ponderado foi escolhido em razão de ser o que melhor reflete a rede produzida.

O grafo acima demostra como a memória do território está correlacionada com seu município de origem, Paranaguá, e com os balneários Praia de Leste e Pontal do Sul. O termo dificuldade aparece relacionado à escola e transporte e estes também conectados à Ilha do Maciel (comunidade tradicional pertencente à região de Pontal do Sul). A relação com Paranaguá aparece como resultado previsível, porém demonstra como suas histórias estão interligadas, assim como a relação de dependência ainda presente. Observa-se que a lembrança sobre o território levanta suas antigas características.

A origem de Pontal do Paraná se dá a partir dos primeiros povos que viviam no local, os índios tupi. Atualmente, residem no local a comunidade Mbya Guarani 
localizada na estrada ecológica do Sambaqui Guaraguaçu. Há ainda outra comunidade que reside no balneário Shangri-lá, conforme levantamento realizado junto à Prefeitura de Pontal do Paraná em 2017.

Ao se tratar da memória e história deste município, primeiramente é necessário nos remetermos a essa população. As perspectivas com base na noção de crescimento apontam para o risco do não reconhecimento dessas comunidades, de seus direitos e seu lugar político. Wachowicz (2000) aponta como as doações apresentavam-se como forma de legitimar a dominação desses povos, seguida da exploração e utilização de sua força de trabalho. Nesse sentido, a naturalização da exploração ocorrida se reverte na banalização da ausência de direitos por parte dessa população.

As literaturas sobre Pontal do Paraná estão relacionadas ao nascimento de Paranaguá. De modo geral, a história do município passa a ser descrita somente a partir do processo de emancipação, o que demonstra a importância desse fenômeno. Todavia, há uma preocupação em resgatar e registrar a história de Pontal, devido ao fato de que: "A história do município está sendo perdida um pouco com a morte dos moradores mais antigos, dos nativos principalmente, parte da história de Pontal vai se perder" (Entrevistado 3).

Sobre o local e o antigo modo de vida, os entrevistados relatam as dificuldades devido principalmente à falta de acesso, de estradas e serviços, a exemplo desses relatos: "Quando eu vim para cá não tinha nem estrada, não tinha nada, tinha que vir pela praia. Tinha uma estrada velha que vinha aqui pelo Guaraguaçu" (Entrevistado 1); "Aqui não tinha comércio em parte nenhuma (...) não tinha uma farmácia” (Entrevistado 7).

A falta de serviços de saúde e de farmácias no local, aliada com a cultura da época, fazia com que os tratamentos de saúde fossem decorrentes de práticas tradicionais de cura. Curador(a), benzedor(a) e parteira, eram agentes de cura e exerciam importantes papéis dentro da comunidade. O benzimento e a utilização de chás eram modos de tratamento das doenças e dos envenenamentos por animais peçonhentos como, por exemplo, a jararaca: "Se você ficava doente você se tratava com folha de pau-velho do mato. Tinha aqueles [....] curadores que não sei como a missão daquelas pessoas é conhecer um pouquinho da medicina" (Entrevistado 7).

Como pode-se observar na figura 3 , o termo nascimento encontra-se vinculado a Paranaguá. Atualmente os partos das moradoras de Pontal do Paraná são realizados na cidade de Paranaguá, em razão da ausência de ofertas desse serviço no município. As crianças acabam por ter seu registro identificado pela cidade de Paranaguá, e não Pontal 
do Paraná. Antes, porém, os nascimentos ocorriam mediante o trabalho de parteiras e, por extensão, os registros eram da localidade de Pontal. Isso reflete na identificação dos moradores. "Hoje a turma fala: 'ah, eu sou pontalense'. Mentira! Nasce tudo em Paranaguá [...]. Eu não, eu nasci aqui... Parteira sabe [...] Então, nós somos pontalense" (Entrevistado 7). Registra-se a importância do conhecimento da parteira que, muitas vezes analfabeta, aprendia bem o seu ofício seguindo o ensinamento de alguém mais velho e experiente, geralmente uma mulher que tinha atuado como parteira ao longo da vida.

Em relação aos modos de produção e troca, os entrevistados destacaram a ausência de comércio local e as dificuldades de comercialização devido às distâncias dos centros de comércio, localizados em Paranaguá. Com isto, a cultura de subsistência imperava, através do cultivo da banana, do arroz, da mandioca e da produção de farinha, tal como atestado nestas narrativas: "a gente sobrevivia daqui mesmo, era o peixe, as roças que plantavam o arroz, o feijão, o milho, plantavam tudo aqui'(Entrevistada 6); "plantava mandioca pra fazer a farinha, banana, arroz, esses troço tudo nós plantava. Só que não tinha despesa, né? Porque acho que eles tinham, não tinham nada... É querosene, luz de querosene, então era muito difícil" (Entrevistado 7). Observa-se que o plantio e a relação com a terra faziam parte dos modos de vida da comunidade.

A ausência de estradas fazia com que muitas vezes fosse necessário realizar o caminho de Pontal do Paraná a Paranaguá a pé. Isso pode ser observado em dois relatos: “Meu pai fez umas oito, dez viagens daqui a Paranaguá pela praia de a pé com saco de compra trazido de Paranaguá pra aqui, porque não tinha aonde comprar aqui" (Entrevistado 7); “Eles iam ou de canoa [...] ou a pé pra ir até Paranaguá” (Entrevistada $6)$.

Em relação a serviços de educação, existiam duas escolas, com oferta de classes multisseriadas, que reúne alunos de várias séries na mesma sala e com o mesmo professor. "Numa sala de aula tinha quatro turmas. Então, primeiro, segundo, terceiro e quarto. [...] Não tinha creche, não tinha esse negócio" (Entrevistado 1).

A Ilha do Maciel, que acolhe uma comunidade tradicional, é lembrada como último local que abrigou uma escola multisseriada. A comunidade passa por desmantelamento de políticas públicas, com dificuldades de acesso a serviços e direitos. Nesse ponto, uma fala remete justamente ao fato de que o fim da escola na própria comunidade gera dificuldades para a população: "Eles têm muita dificuldade para trazer as crianças pra cá, pra Pontal do Sul. Vêm de barco, aí depois mais um ônibus pra vir 
até aqui. Maciel foi a última escola multisseriada aqui no municipio que foi fechada" (Entrevistada 6).

A nomeação do território, no momento anterior à emancipação, ocorria também através da referência ao município de origem: "Aqui se chamava assim: 'as praias de Paranaguá, né? Que era o distrito de Paranaguá" (Entrevistado 1). Inicialmente, o lugar era denominado Barra do Sul, tendo o nome sido modificado oficialmente a partir do processo de emancipação, o que se verifica por meio das certidões de nascimento: "Muitos balneários mudaram de nome, igual Pontal do Paraná era Barra do Sul. Então, a certidão de nascimento da minha mãe é Barra do Sul' (Entrevistada 6).

Little (2015) destaca que a denominação de espaços geográficos ocorre pela linguagem de um grupo e deriva de sua memória coletiva. Ao mesmo tempo, as modificações decorrentes se traduzem pelo controle do território por meio da linguagem: "[...] balneário Atlântica, que depois veio a ser conhecido como balneário Santa Terezinha" (Entrevistado 2); "Eu nasci em Atami, que na época nem era Atami; na época era Pri Ki Mirim” (Entrevistado 7).

As denominações da cidade e região e as mudanças que ocorreram nelas demonstram como o processo de emancipação modificou o modo de referenciar ao lugar. O local onde ocorreu a disputa política acabou influenciando a escolha pelo nome. Foi o balneário de Pontal do Sul, referência na região, que abrigou parte dos acontecimentos do processo de emancipação: “[...] alguns queriam que fosse Pontal do Sul, outros queriam que fosse Praia de Leste. Acabou prevalecendo Pontal do Paraná. [...] até como uma homenagem porque a briga toda foi em Pontal do Sul" (Entrevistado 5).

Verificadas as características que compõem a história do lugar, vale considerarmos o aparato que possibilitou o processo de emancipação. Nesse sentido, a Figura 4 demonstra o contexto constitucional. 


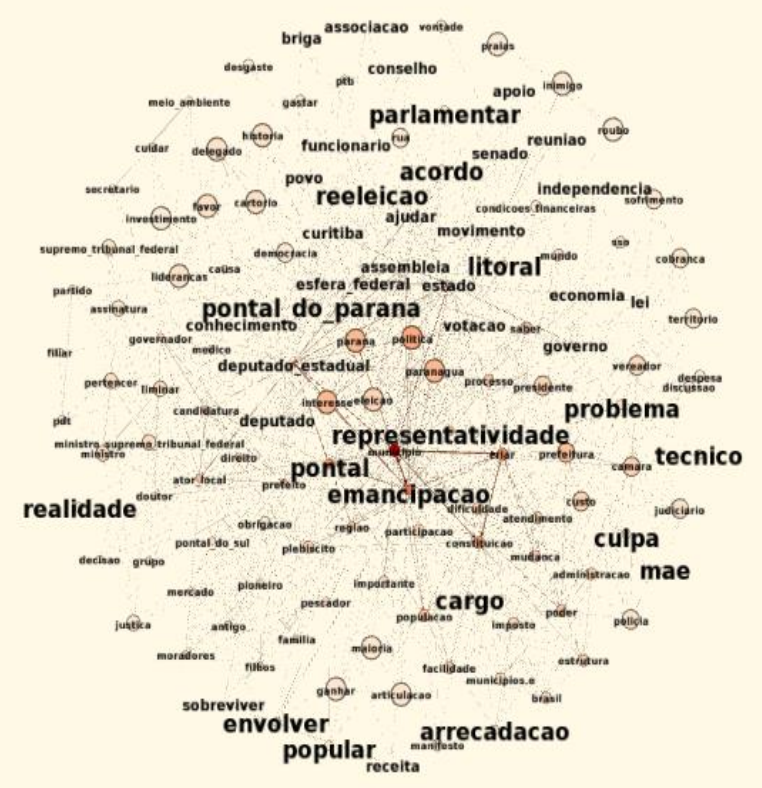

FONTE: Elaboração própria.

A categoria contexto constitucional foi pensada a partir dos dispositivos institucionais, em especial no que se refere aos presentes na Constituição Federal, que contribuíram para o processo de emancipação do município em questão.

A principal ligação apresentada pelo grafo da figura 4 refere-se à triangulação munícipio, constituição e criar, sendo que plebiscito está também correlacionado com criar e município. Uma importante relação também aparece a partir das ligações candidatura, prefeito, governador, ator local. O termo deputado estadual, em importante destaque, possui forte relação com ajudar, ambos correlacionados com assembleia, que possui ligação com movimento. Interesse e política possuem também forte relação. Representatividade está relacionada com Pontal, que se liga à emancipação. Custo está ligado à prefeitura, que apresenta triangulação com os termos câmara e vereador.

Os resultados vão ao encontro das discussões realizadas por Tomio (2002): os mecanismos institucionais não seguem uma lógica socioeconômica, mas estão pautados nas condições constitucionais e são essas condições que possibilitam a interação entre os atores locais. Verifica-se a presença das instituições delimitadoras, no papel do legislativo estadual, e estimuladoras, por meio da legislação que regulamenta a transferência de recursos e, assim, impulsiona o processo.

Os apontamentos de Alves (2006) são reafirmados, uma vez que se observa o amplo controle do legislativo estadual na condução do processo. Nota-se que esse cenário é reconhecido pelos atores envolvidos no movimento. Os resultados demonstram que esse 
cenário repercute na facilidade de aplicação de um novo cenário político no município a ser implantando.

A participação da esfera estadual, no papel do termo deputado estadual, relacionando a assembleia e movimento faz com que se possa refletir a respeito de uma relação direta entre ações na assembleia em direção aos municípios.

O fato de que muitas emancipações estavam ocorrendo no período é reconhecido pelos atores que viabilizaram esta pesquisa: "Na época, ai no estado do Paraná estava acontecendo muitas essas emancipações. Nossa, muita emancipação! 399 municípios tem o estado do Paraná" (Entrevistado 1). "Naquela época, a Constituição, ela era muito flexível para a criação de novos municípios e 28 municípios no estado do Paraná estavam praticamente pronto o processo pra promover uma emancipação" (Entrevistado 4).

O reconhecimento da legislação como chave para a criação de novos municípios é atestado por este entrevistado, que discute as mudanças ocorridas na Constituição, que anteriormente não exigia um plebiscito que envolvesse a participação da população do município de origem: "Só a população de Pontal foi ouvida e a população de Paranaguá não pôde se manifestar, porque a Constituição dizia isso. [...]. Foi a grande mudança que agora dificultou" (Entrevistado 4).

$\mathrm{O}$ entrevistado se refere à mudança na Constituição, que atualmente exige a participação do município de origem, dificultando, assim, a criação de novos municípios. Tal fato pode ser verificado a partir da Emenda Constitucional $\mathrm{n}^{\circ} 15$, de 12 de setembro de 1996, que, em artigo único, aponta que aponta que a criação de Municípios: "far-se-ão por lei estadual, [...] e dependerão de consulta prévia, mediante plebiscito, às populações dos Municípios envolvidos, após divulgação dos Estudos de Viabilidade Municipal, apresentados e publicados na forma da lei” (BRASIL, 1996).

Os custos relativos à criação de novos municípios são apontados pelos entrevistados, que mencionam o fato de Pontal não possuir receita suficientemente capaz de realizar a manutenção de sua estrutura. Isso corrobora a fala de Reis, Costa e Silveira (2013), quando apontam que municípios de pequeno porte por vezes apresentam incapacidade de sustentação financeira em razão do baixo índice de geração de renda. Em alguns relatos essa questão é evidenciada: “Então, o próprio deputado achava que a gente não ia sobreviver aqui [...] Alguns municípios se emancipavam, mas não conseguia sobreviver, não tinha receita" (Entrevistado 1); "As dificuldades econômicas, a sustentação financeira do município era uma questão muito difícil, como ficou provado, aliás, até hoje. Pontal se bate com a dificuldade financeira do município, continua 
dependendo". (Entrevistado 4); "Cada município que você cria, você cria uma despesa enorme para o Estado" (Entrevistado 5).

Os entrevistados destacam os impostos repassados aos municípios, bem como a estrutura administrativa decorrente da sua criação: "é uma barbaridade o que acontece com certos municípios que não tem a menor condição, vive do repasse do FPM, do ICMS e só para sustentar aquela estrutura administrativa sem a menor condição de dar nenhum atendimento à população" (Entrevistado 4); "O excesso de municípios é um custo muito grande pra máquina governamental [...] você tem que criar uma câmara de vereadores, criar uma prefeitura, na sequência vem a comarca, o poder judiciário, polícia, delegacias" (Entrevistado 5).

Essas afirmações corroboram com os apontamentos de Magalhães (2009), sobre a dependência dos municípios das demais esferas e de seus gastos com o legislativo e com pessoal.

A partir deste plano de fundo, a Figura 5 apresenta a categoria relativa ao processo de emancipação de Pontal do Paraná.

FIGURA 5 - CATEGORIA PROCESSO DE EMANCIPAÇÃO 


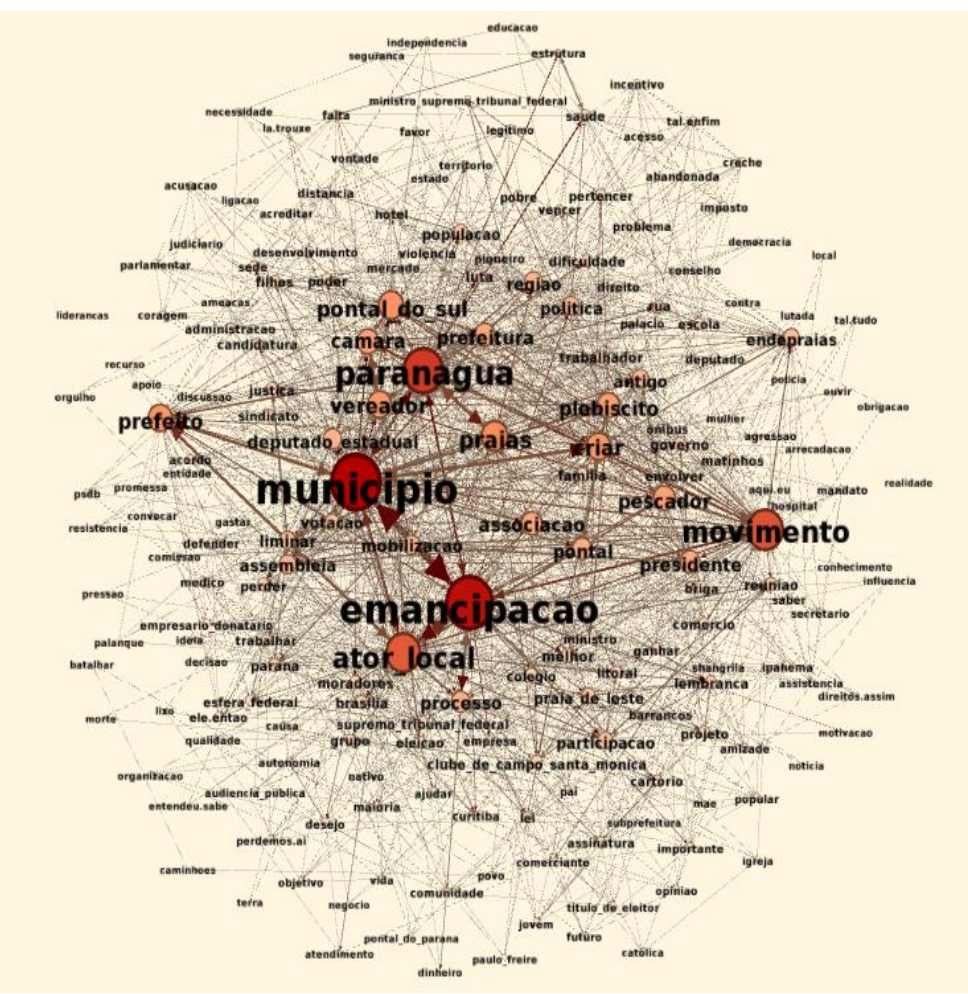

FONTE: Elaboração própria.

$\mathrm{Na}$ figura pode-se visualizar a maneira como ocorreu o processo de emancipação de Pontal do Paraná. Paranaguá encontra-se relacionado com dificuldade, por um lado, e Endepraias, por outro. Endepraias foi o órgão instalado pelo município de Paranaguá para administrar as praias da região durante o período anterior ao processo, a fim de aproximar a administração da população das praias, bem como em uma tentativa de conter o movimento emancipatório. Da mesma forma, Paranaguá encontra-se entre os termos hotel e colégio em referência aos locais onde eram realizadas as reuniões. Observa-se que mobilização possui forte relação com associação, alicerce do processo. Comunidade encontra-se relacionado a processo, que vinculado à lembrança, associa-se a projeto e Praia de Leste. Participação está relacionado com lembrança, projeto e litoral: a lembrança sobre participação encontra-se vinculada a um projeto para o território.

Observa-se a relação reunião e Clube de Campo Santa Mônica, local onde muitos encontros também foram realizados. A relação movimento e empresário aponta a categoria que participou ativamente do processo. Ainda, há a ligação entre emancipação e favor.

As primeiras reuniões a fim de realizar a emancipação ocorreram no ano de 1983 e a partir dos movimentos nessa direção a administração em Paranaguá acabou tomando iniciativas em contraposição a tais ações: “O prefeito da época, José Vicente Elias, ele 
transferiu a sede administrativa da prefeitura pra Pontal do Sul. Com isso não tinha como emancipar o município, cuja sede administrativa estava lá" (Entrevistado 4); "Aí Paranaguá [...] trouxe até a Câmara de vereadores aqui pra dentro do município" (Entrevistado 1); “Com a criação da Endepraias melhorou um pouco a assistência porque eles já sabiam que tinha iniciado o movimento de emancipação" (Entrevistado 3).

Observa-se a forte presença das associações, primeiro modo de organização coletiva local, primeiro experimento democrático. Os entrevistados mencionam que o movimento surgiu a partir do fortalecimento das associações, que eram a referência de administração do local, uma vez que representavam a comunidade. A Associação das Praias do Paraná, o Lions Clube e o Clube de Mães de Praia de Leste foram alguns grupos participantes do processo. A seguir, por meio da formação de um conselho, seu agrupamento facilitou e deu força ao movimento: "O município era administrado mais com as associações. [...] Mas dai surgiu essa ideia, se as associações representam a comunidade, então vamos monta um conselho. [...] Ai pesou, por que tinha uma representatividade grande aqui" (Entrevistado 1).

As reuniões eram realizadas em diferentes lugares, entre os quais: o Clube de Campo Santa Mônica, o baile da Dica, a igreja católica, o restaurante Costelão, o local onde atualmente é a Câmara do município.

Os pescadores constituíram um grupo que participou ativamente do processo, com a participação inclusive de pescadores de outras localidades. Além deles, outros grupos participaram, como os dos pequenos empresários. Quando o município foi criado, contabilizava-se o número de 3.500 eleitores.

Uma das ações realizadas na época, de caráter administrativo, refere-se ao levantamento realizado a fim de fazer o mapeamento do município: " $A$ gente começou a fazer o trabalho de levantamento do município, a mapear [...], levantar pela Copel quantos moradores tinha, quantos terrenos" (Entrevistado 1).

Diante da organização da população e da possibilidade de realização do plebiscito, necessário à realização da emancipação, Paranaguá entrou com uma liminar na tentativa de barrar o processo: "Entramos com uma ação no Tribunal de Justiça do Paraná e conseguimos uma liminar impedindo a realização desse plebiscito, o que era pré-requisito [...] Não deu certo; acabou indo parar em Brasília, no Supremo" (Entrevistado 4).

Houve mobilização de setores do município de origem, através de manifestações. Diante de tais situações, observa-se a disputa pelo território, a busca pela 
emancipação a fim de gerar mudanças na administração e, assim, controle do local: " $O s$ vereadores, o presidente da Câmara, a associação comercial, os trabalhadores [...] carro de som no dia da votação. Não tenho notícia de nenhum outro que tenha tido tanto empenho [...] como foi aqui" (Entrevistado 4).

Ante a liminar apresentada, o grupo de Pontal do Paraná reagiu através do Supremo Tribunal Federal, conforme observado nesses relatos: "Então eu custiei viagem dele pra Brasília, pra ele ir ao Supremo Tribunal Federal, porque Paranaguá entrou como uma liminar [...] E conseguimos derrubar essa liminar" (Entrevistado 5). "Foi cassada a liminar do Tribunal de Justiça pelo ministro Sepúlveda Pertence e Pontal pôde fazer o seu plebiscito e a partir daí, então, todos os pré-requisitos estavam preenchidos" (Entrevistado 4).

A realização do plebiscito foi um momento apresentado como marcante no processo: "No plebiscito que nós fizemos, 1648 votaram: 1450 pelo sim, 159 pelo não, 17 brancos e 22 nulos". (Entrevistado 5); "Eu acho que a gente conseguiu mobilizar cem por cento das pessoas, ali moradores, para que participassem desse processo, na época... Que precisou ir em cartório, reconhecer assinatura em cartório" (Entrevistada 6); "Eu acho que o que mais marcou a gente foi a votação do plebiscito. Quando o ministro liberou pra gente fazer o plebiscito [...] foi uma festa na cidade aqui muito grande" (Entrevistado 3).

Dito isso, pode-se dizer que, por meio das falas dos entrevistados, foi possível reconstruir o processo de emancipação do município de Pontal do Paraná com a utilização da análise de redes semânticas e fazer alguns apontamentos finais.

\section{Considerações finais}

Diante dos resultados alcançados, por meio da utilização da história oral e da metodologia de análise estrutural de redes utilizada para categorizar o conjunto de discursos oferecidos por atores políticos participantes do processo de emancipação de Pontal do Paraná, foi possível compreender o contexto em que ocorre o processo de emancipação de Pontal do Paraná.

Pode-se verificar que o processo ocorre a partir de um lugar que apresenta dificuldades de acesso a serviços essenciais, marcado pela distância dos centros de atendimentos, mas que perante tais condições guarda práticas e saberes em profunda ligação com o lugar - como a utilização de técnicas de cura e benzimento e com a 
tradicional cultura da pesca, bem como o manejo de produtos tradicionais, como a mandioca. Ao mesmo tempo, tais discussões trouxeram à tona a progressiva diminuição de oferta de políticas públicas em uma comunidade tradicional, como no caso da Ilha do Maciel.

Foi possível verificar que o contexto do processo em Pontal do Paraná reafirma proposições oferecidas pelos estudos de processos emancipatórios. A emancipação em questão ocorre em um período em que a Constituição Federal fornecia facilidades à formação de novos municípios, prevendo a ocorrência de plebiscito somente no município a ser emancipado e oferecendo repasses estimuladores ao processo. Isso, somado ao fato de que tal criação se encontrava submetida ao legislativo estadual, que na época tinha um grande defensor da emancipação: o deputado Aníbal Khury.

Acredita-se que as discussões apresentadas e os resultados alcançados podem contribuir para futuros estudos sobre os processos de emancipação municipal e demais ações coletivas em direção ao território. Observa-se ainda que a metodologia utilizada pode ser adequada para estudos nesse sentido.

Por fim, como nascimento político do município e, portanto, como importante acontecimento histórico, a demarcação dos espaços que fizeram parte do movimento possivelmente poderá fazer com que a história vivenciada seja futuramente transmitida e localizada. É o caso, por exemplo, do Clube de Campo Santa Mônica. A menção do envolvimento de tal espaço no processo pode vir a propiciar o sentimento de pertencimento, bem como a lembrança de uma ação coletiva relacionada ao lugar.

\section{Referências}

ALVES, Alessandro. Cavassin. O contexto institucional e a relação entre Executivo e Legislativo na criação dos municípios no Paraná, 1988 a 1996. Curitiba: UFPR, 2006. Dissertação (Mestrado em Sociologia) - Programa de Pós-graduação em Sociologia, Setor de Ciências Humanas, Letras e Artes, Universidade Federal do Paraná, Curitiba, 2006.

BRASIL. Constituição (1988). Constituição: República Federativa do Brasil. Brasília, DF: Senado Federal, 1988.

BRASIL. Emenda Constitucional. $n^{\circ} 15,12$ de setembro de 1996. Disponível em: $<$ https://goo.gl/wFCSvX>. Acesso em: 11 jun. 2017. 
BREMAEKER, François. E. J. Os municípios brasileiros. In Observatório de Informações municipais, 2013. Disponível em: $<$ http://www.oim.tmunicipal.org.br/index.cfm>. Acesso em: 25 mai. 2017.

. Os novos municípios: surgimento, problemas e soluções. In Observatório de informações municipais, $1992 . \quad$ Disponível em: $<$ http://www.oim.tmunicipal.org.br/index.cfm>. Acesso em: 28 maio 2017.

BRANDT, Cristina. Thedim. "A criação de municípios após a Constituição de 1988. O impacto sobre a repartição do FPM e a Emenda Constitucional n 15, de 1996." In Revista de informação legislativa, Brasília, jul./set. 2010, v. 47, n. 187, p. 59-75.

CAMPOS, Mayã. Polo. Mulheres vítimas de violência sexual e os significados de suas experiências corporais e espaciais: teu corpo é o espaço mais teu possível. Dissertação (Mestrado em Gestão do Território) - Programa de Pós-graduação em Geografia, Setor de Ciências Exatas, Universidade Estadual de Ponta Grossa, Ponta Grossa, 2016.

CIGOLINI, Adilar. Antonio. A fragmentação do território em unidades políticosadministrativas: análise de criação de municípios no Estado do Paraná. Dissertação (Mestrado em Geografia) - Programa de Pós-graduação em Geografia, Departamento de Geociências do Centro de Filosofia e Ciências Humanas, Universidade Federal de Santa Catarina, Florianópolis, 1999.

CITADINI, Roque. Antonio. Municípios inviáveis e controle do déficit público. Jornal Diário Comércio e Indústria. 22 e 25 de nov. 1998.

DESLANDES, Suely. Ferreira; NETO, Otávio. Cruz; MINAYO, Maria. Cecília. Souza. (Orgs.). Pesquisa social: teoria, método e criatividade. Petrópolis, Vozes, 2007, p.7 - 80.

FAVERO, Edison. Desmembramento territorial: o processo de criação de municípios - Avaliação a partir de indicadores econômicos e sociais. p.278 Tese (Doutorado) Escola Politécnica da Universidade de São Paulo. Departamento de Engenharia de Construção Civil - São Paulo, 2004.

GOMES, Gustavo. Maia; MAC DOWELL, Maria. Cristina. Descentralização política, federalismo fiscal e criação de municípios: o que é mau para o econômico nem sempre é bom para o social. In Ipea, Brasília, 2000. Disponível em: $<$ http://www.ipea.gov.br/portal/index.php>. Acesso em: 02 jun. 2017.

HALBWACHS, Maurice. A memória coletiva. São Paulo, Biblioteca Vértice, 1990, p 985.

Instituto Brasileiro de Geografia e Estatística. IBGE. Cidades@. Rio de Janeiro, IBGE, 2014. Disponível em: < https://cidades.ibge.gov.br/ >. Acesso em: 10 maio 2017.

INSTITUTO PARANAENSE DE DESENVOLVIMENTO ECONÔMICO E SOCIAL (IPARDES). Caderno Estatístico de Pontal do Paraná. Curitiba, 2017. Disponível em: < http://www.ipardes.gov.br/>. Acesso em: 19 de jun. 2017.

LEMIEUX, Vicent; MATHIEU, Ouimet. Análise estrutural das redes sociais. Lisboa, Instituto Piaget, 2004. 
LITTLE, Paul. Elliott. "Desenvolvimento territorial sustentável: desafios e potencialidades para o século XXI". In Guaju, Matinhos, UFPR, jul./dez. 2015, v. 1, n. 2, p. 127-143,

MAGALHÃES, João. Carlos. "Emancipação político-administrativa dos municípios no Brasil”. In: Dinâmica dos municípios. Brasília, Ipea, 2009. p.13-52.

QUEIROZ, Maria. Isaura. Pereira. "Relatos orais: do "indizível" ao "dizível"”. In: Experimentos com histórias de vida: Itália-Brasil. São Paulo. Vértice. Revistas dos Tribunais, 1987.

REIS, Paulo; Ricardo Costa; COSTA, Thiago. Melo. Teixeira; SILVEIRA, Suely. Fátima. Ramos. "Receita pública e bem-estar social nos municípios mineiros emancipados no período de 1988 a 1997”. In Revista Eletrônica de Administração, Porto Alegre, ed. 74, jan./abr. 2013, v. 1, p. 61-82.

RICOEUR, Paul. A memória, a história e o esquecimento. $6^{\mathrm{a}}$ ed. Campinas, Unicamp, 2007, p.103-137.

ROCHA, O. A. Subsídios para a história de Pontal do Paraná. Curitiba, Gráfica e Editora Núcleo Ltda., 1997.

SANTOS, Maria. Sônia; ARAUJO, Osmar. Riberio. "História oral: vozes, narrativas e textos". In Cadernos de História da Educação, Uberlândia, EDUFU, jan./dez. 2007, n. 6, p. 191-201.

SANTOS, Ronaldo. Alencar; ANDRADE. Priscilla. Lopes. "A evolução histórica do federalismo brasileiro: uma análise histórico-sociológica a partir das Constituições Federais". Disponível em:

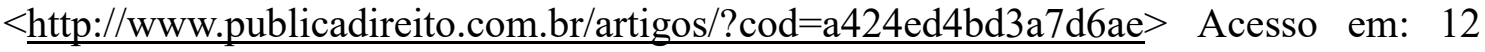
ago. 2015.

SILVA, Edson. Armando; SILVA, Joseli. Maria. "Ofício, Engenho e Arte: inspiração e técnica na análise de dados". In Revista Latino-Americana de Geografia e Gênero, Ponta Grossa, 2016, v. 7, n. 1, p. 132- 154.

SOUZA, Celina. "Federalismo, desenho constitucional e instituições federativas no Brasil pós-1988”. In Revista Sociologia e Política, Curitiba, UFPR, jun. 2005, n. 24, p. 105121.

TOMIO, Fabricio. Ricardo. Lima. "A criação dos municípios após a Constituição de 1988”. In Revista Brasileira de Ciências Sociais, São Paulo, ANPOCS, 2002, v. 17, n. 48.

WACHOWICZ, Ruy. Christovam. A história do Paraná. Ponta Grossa, Editora UEPG, 2010.

Recebido em: 01 mar. 2019.

Aceito em: 30 maio 2019. 